\section{RFP-2514}

November 19, 1976

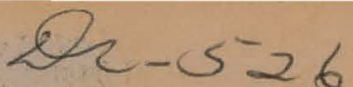

RFP-2514

November 19, 1976

\title{
THE NATURE OF MERCURY-ACTIVATED
}

\section{SILVER SOLID-STATE BONDS}

Virgil K. Grotzky

Clyde R. Rice

Joe H. Doyle

Dave L. Olson

Research and Development

PHYSICAL METALLURGY GROUP

\section{Rockwell International}

Atomics International Division

Rocky Flats Plant

P.O. Box 464

Golden, Colorado 80401

U.S. ENERGY RESEARCH AND DEVELOPMENT ADMINISTRATION CONTRACT EY-76-C-04-3533

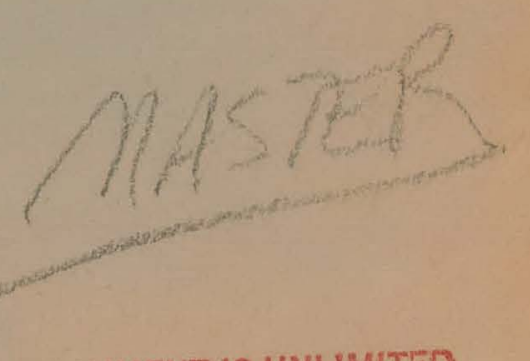




\section{DISCLAIMER}

This report was prepared as an account of work sponsored by an agency of the United States Government. Neither the United States Government nor any agency Thereof, nor any of their employees, makes any warranty, express or implied, or assumes any legal liability or responsibility for the accuracy, completeness, or usefulness of any information, apparatus, product, or process disclosed, or represents that its use would not infringe privately owned rights. Reference herein to any specific commercial product, process, or service by trade name, trademark, manufacturer, or otherwise does not necessarily constitute or imply its endorsement, recommendation, or favoring by the United States Government or any agency thereof. The views and opinions of authors expressed herein do not necessarily state or reflect those of the United States Government or any agency thereof. 


\section{DISCLAIMER}

Portions of this document may be illegible in electronic image products. Images are produced from the best available original document. 


\section{LEGAL NOTICE}

This report was prepared as an account of work sponsored by the United States Government. Neither the United States nor the Energy Research and Development Administration, nor any of their employees, nor any of their contractors, subcontractors, or their employees, makes any warranty, expressed or implied, or assumes any legal liability or responsibility for the accuracy, completeness or usefulness of any information, apparatus, product or process disclosed, or represents that its use would not infringe privately owned rights.

Printed in the United States of America

Available from the

National Technical Information Service

U. S. Department of Commerce

Springfield, Virginia 22161

Price: Printed Copy $\$ 4,50$-Microfiche $\$ 3.00$

Price Is Subject to Change Without Notice 
Printed

November 19, 1976
RFP-25 14

UC-25 MATERIALS

TID-4500-R64

\title{
THE NATURE OF MERCURY-ACTIVATED SILVER SILVER SOLID-STATE BONDS
}

\author{
Virgil K. Grotzky \\ Clyde R. Rice \\ Joe H. Doyle \\ Dave L. Olson
}

Research and Development

PHYSICAL METALLURGY GROUP :

SUBJECT DESCRIPTORS

Solid State Bonding

Beryllium

Scanning Electron Microscopy

ROCKWELL INTERNATIONAL ATOMICS INTERNATIONAL DIVISION ROCKY FLATS PLANT

P.O. BOX 464

GOLDEN, COLORADO 80401

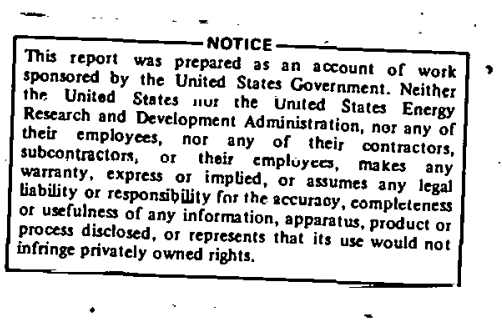

Prepared under Contract EY-76-C-04-3533

for the

Albuquerque Operations Office

U. S. Energy Research and Development Administration 


\section{CONTENTS}

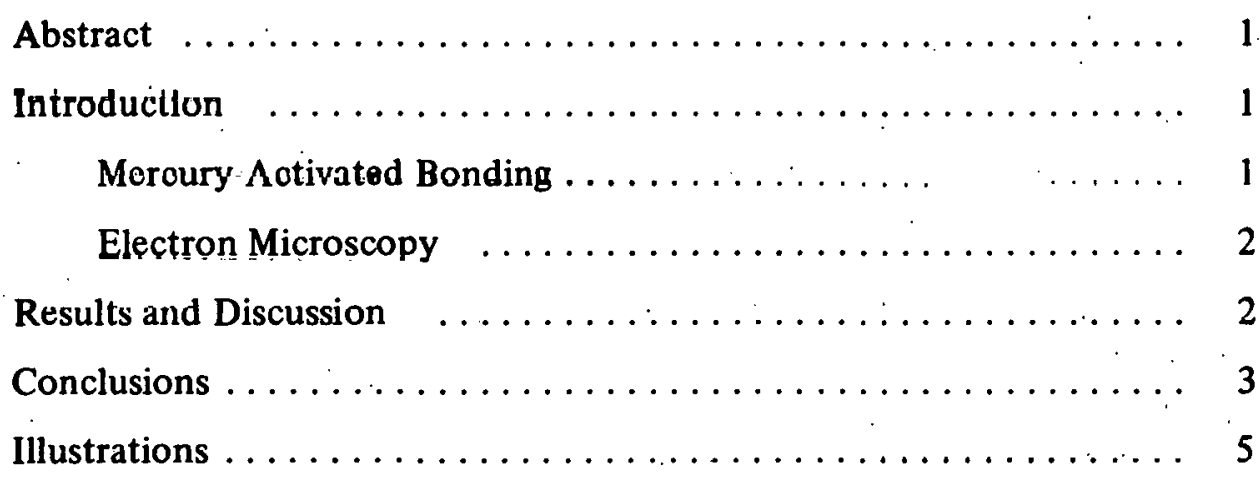

(Figures 1 through 14) 


\title{
THE NATURE OF MERCURY-ACTIVATED SILVER SOLID-STATE BONDS
}

\author{
Virgil K. Grotzky, Clyde R. Rice, Joe H. Doyle, and Dave L. Olson
}

\begin{abstract}
A mercury-enhanced silver solid-state bond has produced reliable high strength joints in the bonding of Vascomax-250 (maraging steel). The joints are achieved by applying a uniform bond pressure across the mercury-activated silver-coated bonding surfaces at low temperatures. Mercury assists in making reproducible bonds by being an effective surface conditioner prior to bonding. The fractured surface morphology was analyzed by scanning electron microscopy and energy dispersive X-ray analysis.
\end{abstract}

\section{INTRODUCTION}

Silver solid-state bonding which produces high strength joints at low temperatures has the potential of alleviating many of the production joining problems, associated with thermal distortion. These high strength joints are the result of triaxial tensile stresses in the thin-silver intermediate layer that minimizes the chear stress within the loaded joint. This prevents appreciable plastic deformation in the joint and results in joint tensile strengths which are many times larger than the bulk ultimate tensile strength of the silver.

These joints are achieved by applying a uniform bonding pressure across the silver-coated bonding surfaces at low temperatures. The uniform pressure is accomplished with a well-aligned fixture design. The bonding pressure is applied to these joints with a hydraulic press and the bonding temperature is achieved by induction heating. The bonding pressure is maintained on the joint through the complete bonding temperature cycle. Bonding temperatures from 200 to $800^{\circ} \mathrm{F}\left(93.3\right.$ to $426.7^{\circ} \mathrm{C}$ ) and bonding pressures up to 30 thousand pounds per square inch [210 megapascals (MPa)] have been investigated.

Essential to this joining process is the adherence of the silver coating to the substrate. These silver coatings have been deposited by both vapor deposition (hollow cathode sputter-evaporation deposition) and electrodeposition processes. Silver coatings of thicknesses ranging from 0.0002 to 0.0009 inches have been successfully used.

Silver solid-state joints have demonstrated strengths as high as $812 \mathrm{MPa}(116 \mathrm{ksi})$. There has been a large variation in mechanical behavior of these joints with a definite need to achieve reliable and reproducible joint properties. Roughness and contamination on the silver surface are major sources of mechanical defects in the joints which exhibited the lower tensile strengths. This report is concerned with a technique of reducing the influence of these defects on the integrety of the silver solid-state joints.

\section{Mercury-Activated Bonding:}

Findings show that the application of a mercury coating on the top of the silver deposition, prior to applying the bonding pressure, will produce reliable and reproducible high strength joints. Such joints have been achieved for both tensile specimens and specimens of complex shapes. The mercury coating has been found to allow high strength joints to be formed with stained silver depositions. This apparent cleaning function has removed much of the concern over the storage time of unbonded silver-coated parts. The application of mercury has also allowed successful joints to be made with inferior surface flatness. With these forgiveness qualities being realized, the 
role of mercury in the atomic processes of achieving a silver solid-state bond is of definite interest.

The application of mercury was first performed by immersing the silver-coated surface into mercury and obtaining a wetted surface. The excess mercury was removed by shaking. The immersed specimens had a thick mercury layer which caused excessive mercury vapor emissions during the bonding process. A much thinner mercury layer was obtained by electrodepositing the mercury onto the silver using a cyanide electroplating solution. This permitted mercury-film thicknesses of the order of 20 millionths of an inch to be formed. This electrodeposition technique is reproducible and production-oriented.

\section{Electron Microscopy:}

The microstructure and chemical constitution across a mercury-enhanced silver solid-state bond was investigated by using scanning electron microscopy with an energy dispersive X-ray analyzer. The investigation was performed on silver-coated Vascomax 250 (maraging steel) joints. These joints were bonded at $800^{\circ} \mathrm{F}$ $\left(427^{\circ} \mathrm{C}\right)$ for 10 minutes with the assistance of a mercury coating.

\section{RESULTS AND DISCUSSION}

An optical micrograph of a fracture of silver solidstate bond is seen in Figure $1 .^{1}$ The mercuryassisted bond fractured, leaving two definite contrasts on the micrograph, a grey and a white region. Figure 2 shows enlargement of this fracture surface (20X) and illustrates that the contrast shown in Figure 1 is the result of definite morphological differences on the surface. Figure 3 illustrates the ductile dimpling type fracture in the white region. This figure also gives an excellent view of the nature of the silver-silver interface since it shows the edge of the top silver layer on the bottom silver layer. Figure 4 is a micrograph

\footnotetext{
' Figures appear at the end of text.
}

of this edge at higher magnification which shows definite metallic bonding between these silver coatings.

Figure 5 shows the morphology in the grey region. The grey region does not have the ductile-dimpling fracture behavior that is representative of a fracture along the silver-silver interface. It appears that the grey regions are fracture surfaces between the maraging steel and silver, and the white regions are associated with fracture along the silver-to-silver interface. This is further verified by energy dispersive. $X$-ray analysis of a white-to-grey transition region on the fractured surface (Figure 6 ). The elemental analysis of this surface is shown for silver (Ag) (Figure 7), mercury ( $\mathrm{Hg}$ ) (Figure 8), and nickel (Ni) (Figure 9). Tigure 7 docs show major silvei cuncentration as expceted, but with somo depletion in specific regions that are difficult to identify one-to-one with the surface morphology seen in Figure 6. Presence of mercury was found across the surface, but with definite depletion on regions identified as grey regions in Figure 6. Figure 9 indicates that the grey regions have high concentrations of nickel. This supports the fact that these silver coatings on the maraging steel were electrodepositions and that the Vascomax-250 surfaces had a nickel strike prior to silver plating. This further identifies the grey regions as fracture surface between the silver and the steel. It is expected that the fracture of this tensile bar was initiated at the stecl-silver interface and only later propagated into the silver-silver interface.

A few small isolated unbonded regions have been located on the fracture surface in the white regions (on the fractured silver-silver interface) as is shown in Figure 10. Such defects have been found on silver-bonded surfaces without mercury activation and have been related to small surface irregularity (high spots) and contamination. It is thought that mercury activation reduces the number and size of such defects.

These micrographs from fractured bonded joints which had acceptable strength illustrates that mercury is definitely present in the joint and causes no major deviation in the desired mechanical 
behavior of the bonded joint. Thus, mercury can be used as an effective surface conditioner prior to bonding.

The microstructure was also investigated by use of metallographic procedures and optical microscopy. Optical micrographs of the joint are shown in Figures 11 and 12. These micrographs are of excellent quality considering the major problems associated with the preparation of dissimilar metal specimens, especially when one of the materials is as soft as silver.

Figures 11 and 12 both show a two-phase structure in the mercury-activated silver indicating that during the bonding cycle sufficient time and temperature were achieved to allow the mercury to diffuse from the surface into and throughout the silver.

The two-phase structure is most likely a silvermercury intermetallic phase, the dark precipitates, dispersed throughout the silver rich-mercury solid solution (Figure 13). ${ }^{2}$ The two-phase structure will surely increase the strength and lower the ductility of this silver intermediate layer of the joint. This should further assist in achieving high strengths from this constraint joint. Also note on Figures 11 and 12 the thin nickel strike between the silver coating and the maraging steel.

Figure 14 shows a concentration scan for mercury acruss a fractured silver solid-state bond which has been mercury-activated prior to bonding. Notice the mercury has not stayed on the silver-silver bonded interface, but has migrated at least half way across the silver. From measuring peak heights and comparing with standards, it was determined that the silver-to-silver bonding region has a composition of approximately 75 percent silver, 25-percent mercury. From the equilibra phase diagram (Figure 13), it is inconsistent to have a two-phase structure as observed in Figure 11 and 12 with a solid solution of $\mathrm{Ag} 25$-percent $\mathrm{Hg}$. At least 35 percent $\mathrm{Hg}$ in the solid solution is

\footnotetext{
${ }^{2}$ M. Hansen. Constitution of Binary Alloys. Second Edition. McGraw-Hill Book Company, Inc., New York. 1958.
}

needed before precipitation will occur. Further work is necessary to alleviate these questions.

Figure 14 also indicates that the major mercury concentration has not reached the nickel strike with the bonding time and temperature used. Further work at longer times and higher temperatures should be performed for various materials being bonded by mercury-activated silver to investigate the effect of mercury on the silversubstrate adhesion.

Also further mercury activation studies should be performed at lower bonding temperatures and longer bonding times to determine if these high strength joints can be achieved at even lower temperatures. From the experience of dental use of $\mathrm{Ag}-\mathrm{Hg}$ alloys in achieving desired mechanical behavior, much lower temperature joints should be possible.

\section{CONCLUSIONS}

1. Mercury activation assists in making reproducible and reliable silver solid-state joints without any apparent microstructural disadvantages.

2. Mercury does not stay at the bonding surface but migrates into silver and strengthens the silver layer through the formation of solid solution and precipitates.

3. Mercury-activated silver bonds have the same ductile-dimpling fracture mode as nonactivated bonds. Mercury assists in making reproducible bonds by being an effective surface conditioner prior to bonding. Mercury appears to alleviate problems associated with surface roughness and contamination.

4. The fractured surface morphology of mercuryactivated silver solid-state bonds has been documented and analyzed. 
RFP-25 14

\section{THIS PAGE \\ WAS INTENTIONALLY \\ LEFT BLANK}


I L L U S T R A T I O N S

Figures 1 through 14

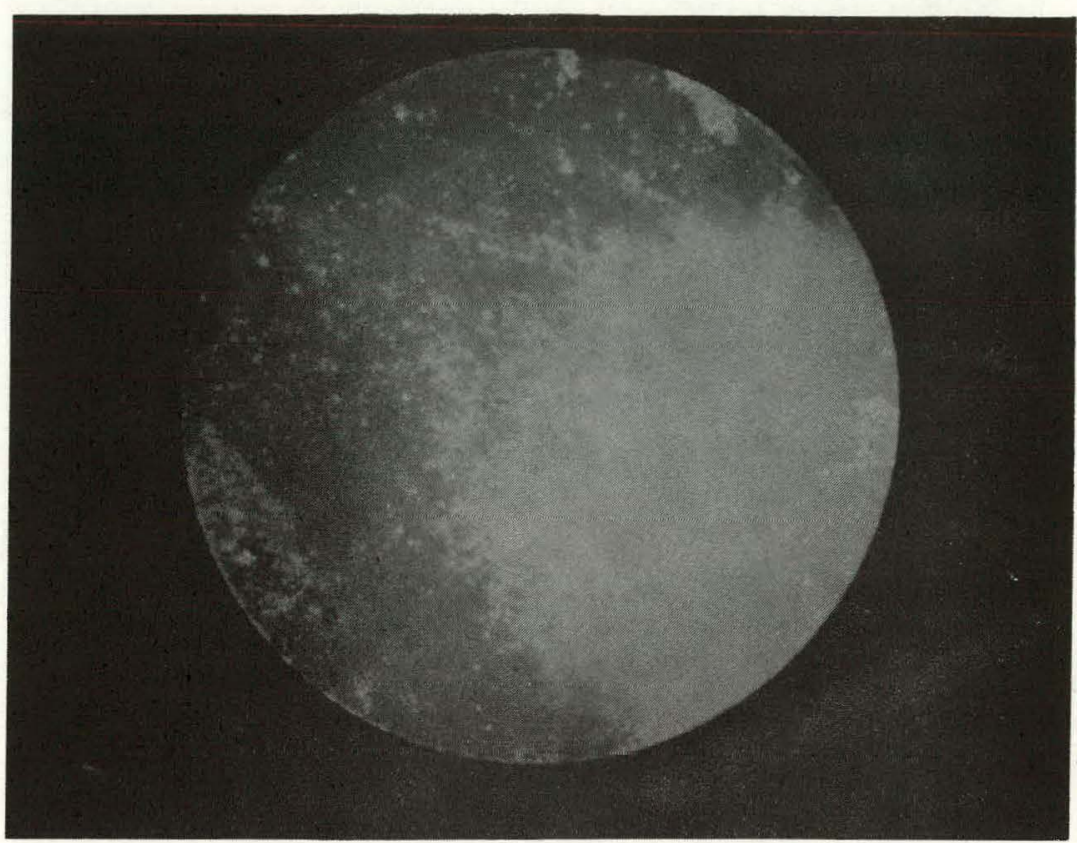

FIGURE 1. Optical Micrograph. The fracture of a tensile-tested silver solid-state bond with mercury assist is shown. The light area was silver-to-steel separation, while the dark area was silver-to-silver separation. Magnification 7X.

FIGURE 2. A higher magnification of the fracture tensile-bar surface shown in Figure 1. Note the two different surface morphologies resulting in the different contrast. This is a scanning electron micrograph. The color shading is reversed from the optical photograph above. Magnification 20X.

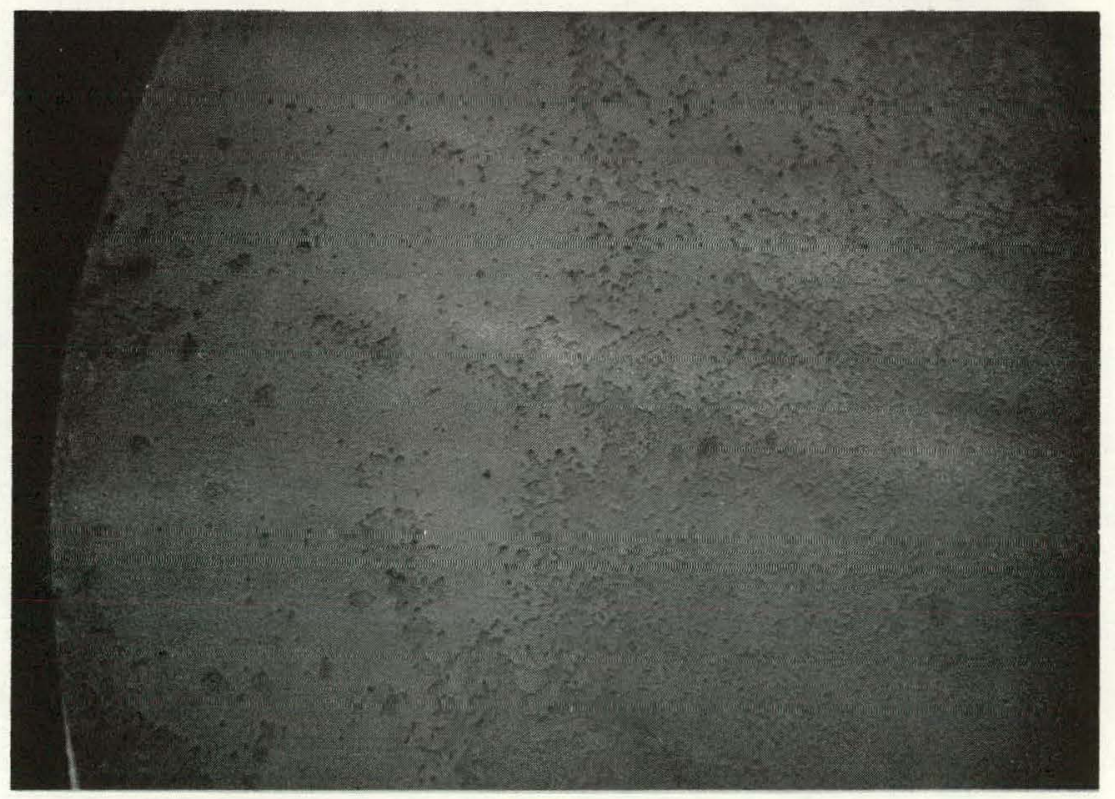


RFP-2514

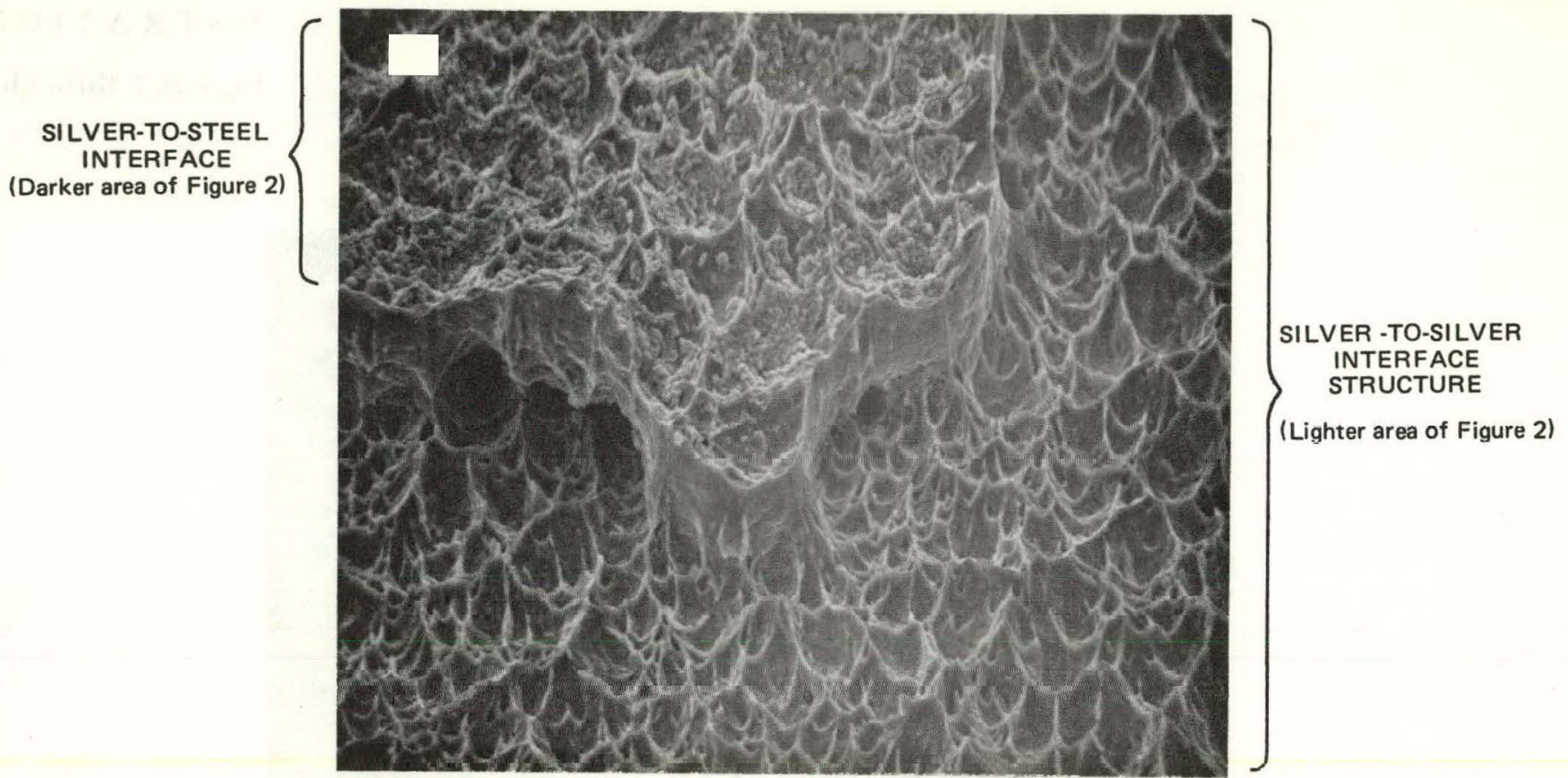

FIGURE 3. Scanning electron micrograph showing the ductile dimpling-type fracture at the silver-silver interface of a mercury assisted bond (white region of Figure 2). The fragment in the upper portion of the photograph is where the top silver layer pulled loose from the substrate (dark grey region of Figure 2). Magnification 1000X.

FIGURE 4. Higher magnification of the edge region shown in Figure 3. Note the definite metallic bonding between these silver coatings. Magnification 2000X.

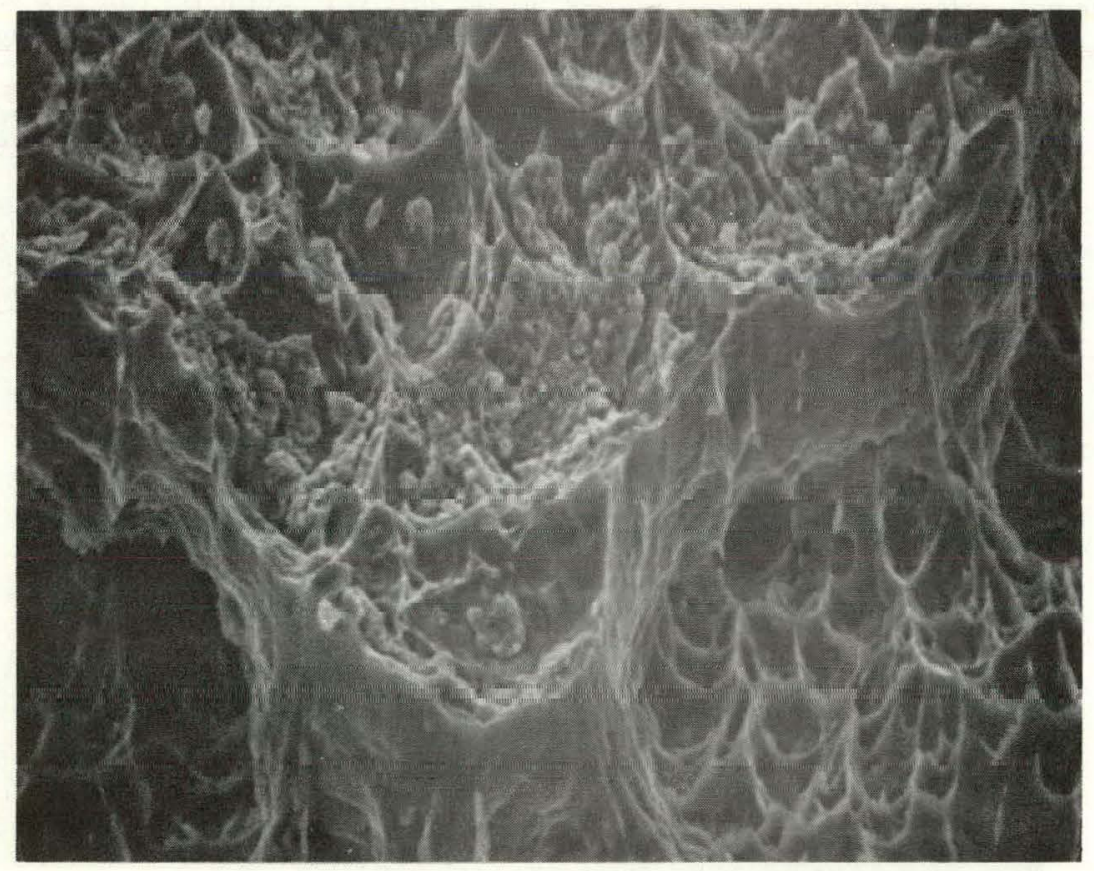


FIGURE 5. The scanning electron micrograph of the fracture surface in a grey region. The fracture mode appears to be a shear pattern. Magnification 2000X.

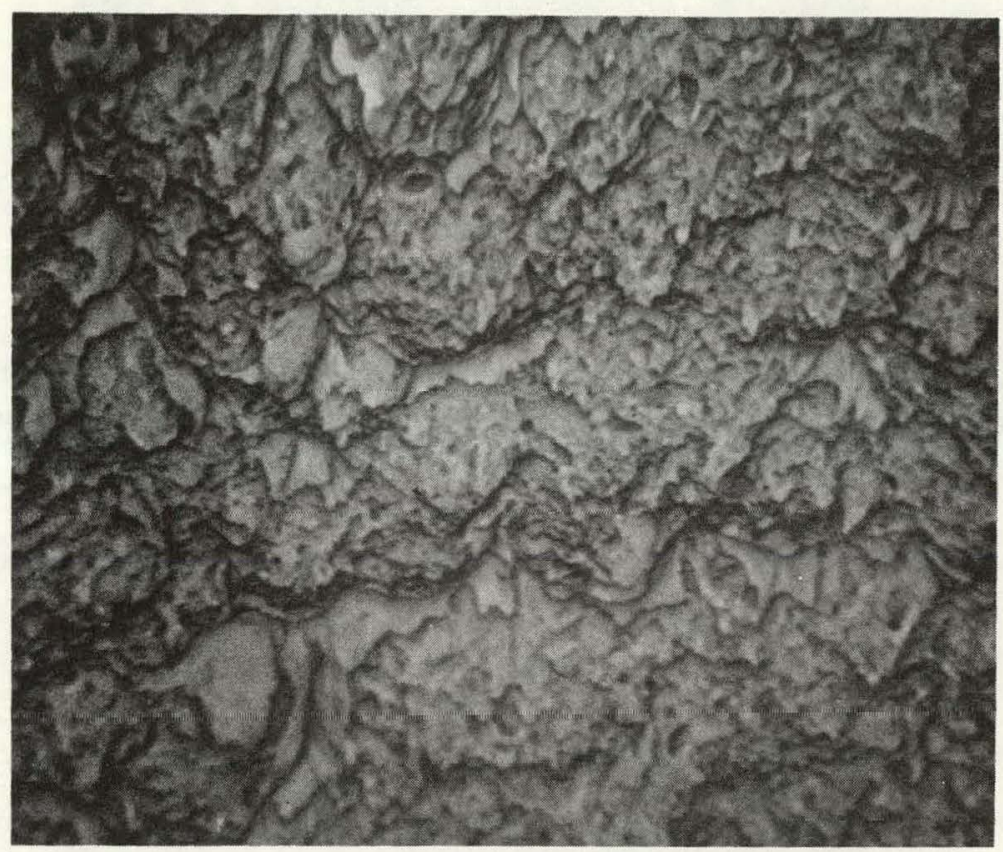




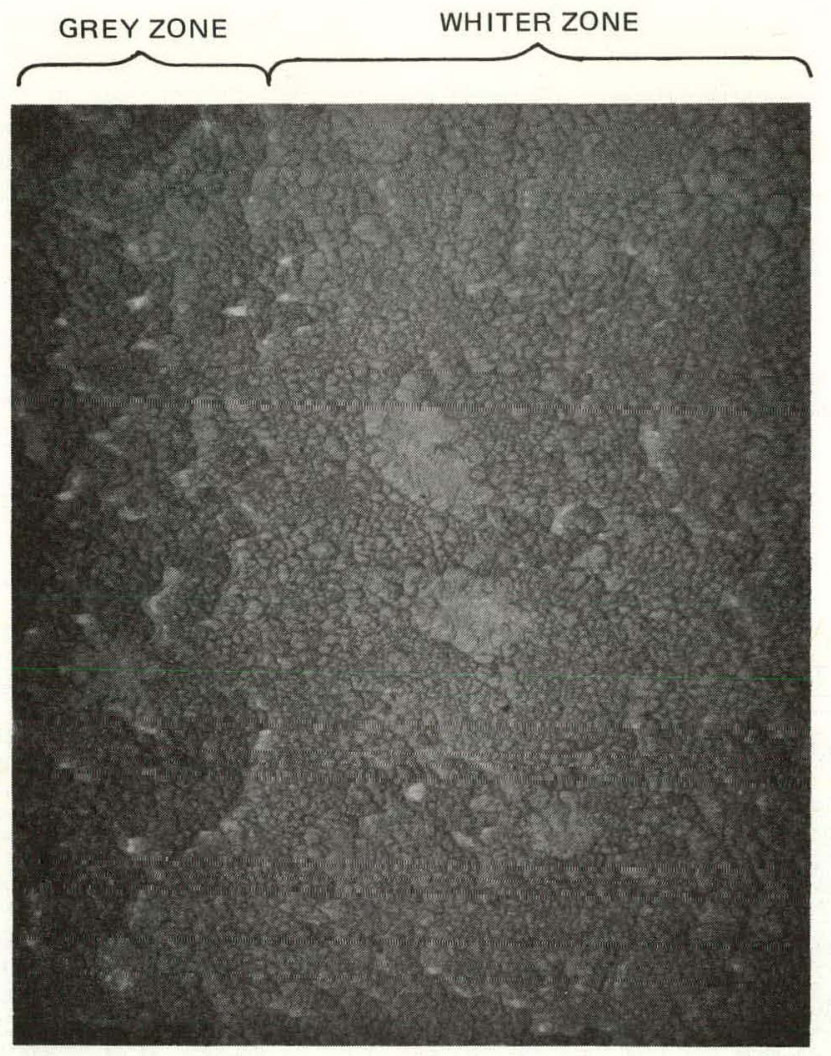

FIGURE 6. The grey-to-white transition zone shown in Figure 2. The adjacent micrographs are raster scans of this area showing the location of the elements present. Magnification 100X.

FIGURE 7. The location of silver concentration on the fractured bond surface. Magnification 100X.

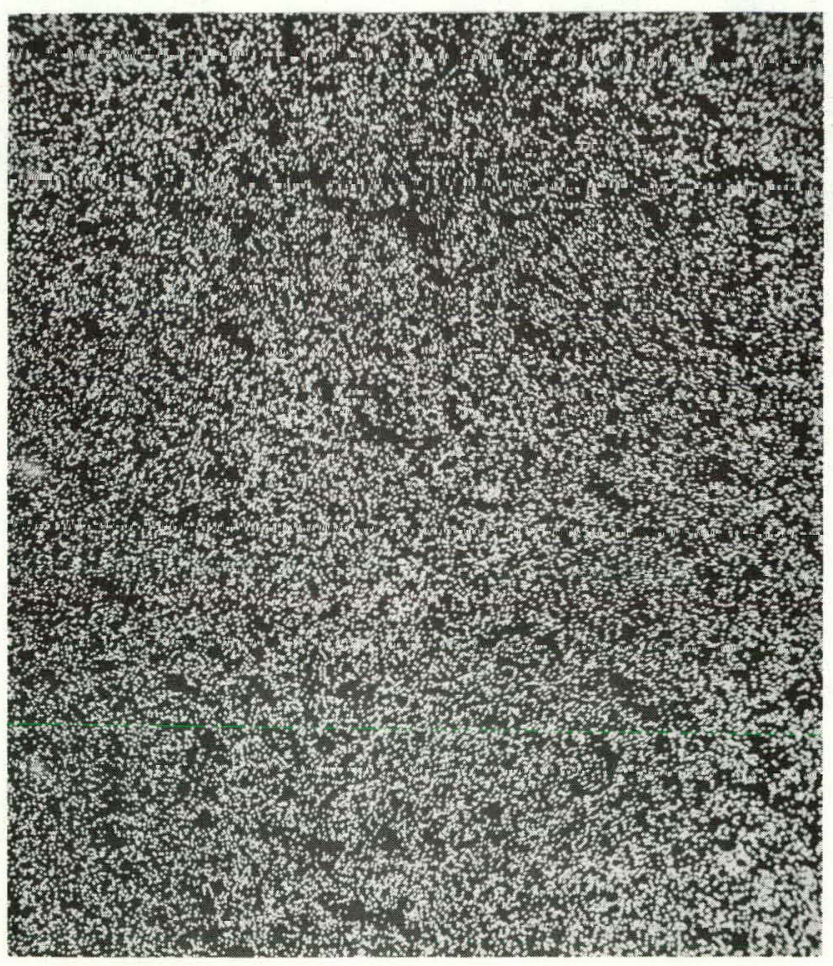




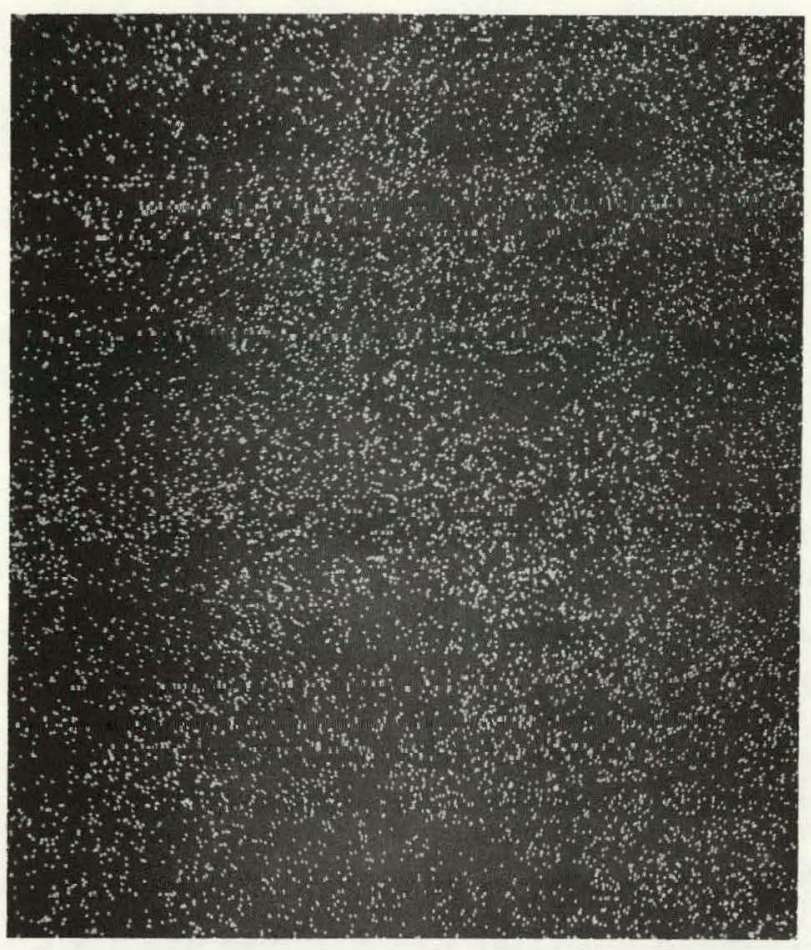

FIGURE 8. The location of mercury on the fractured bond surface. Magnification 100X.

FIGURE 9. The location of nickel concentration on the fractured bond surface. Magnification 100X.

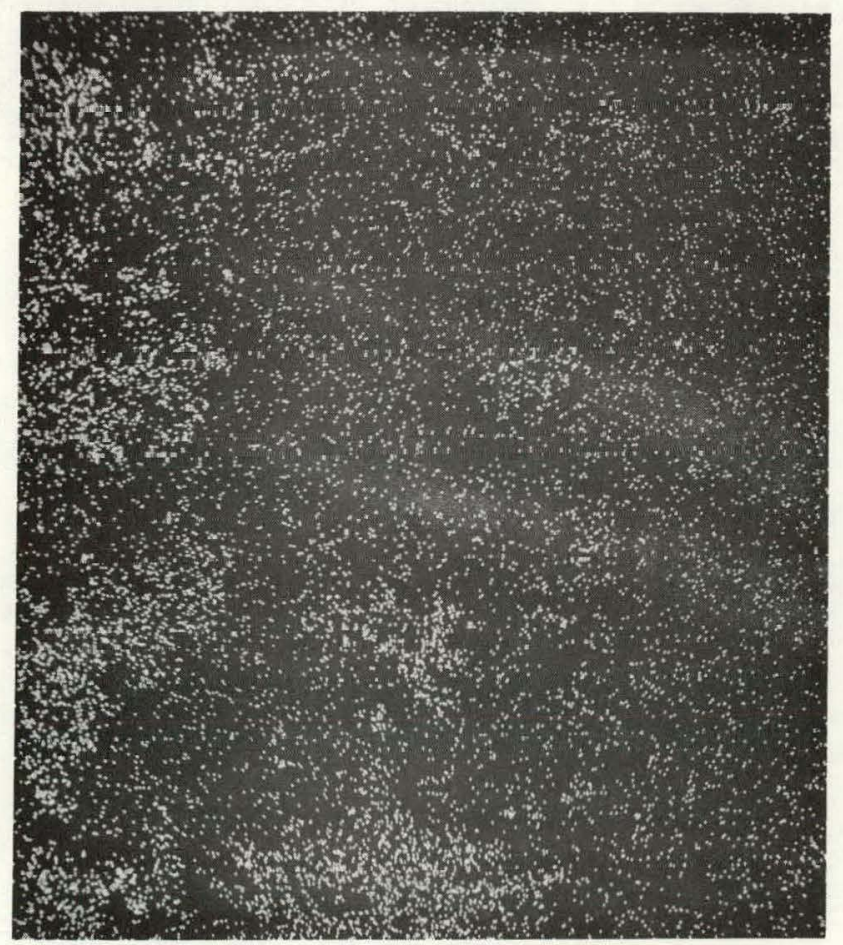


FIGURE 10. A small unbonded region on the fractured silver-silver bonded interface. Magnification 475X.

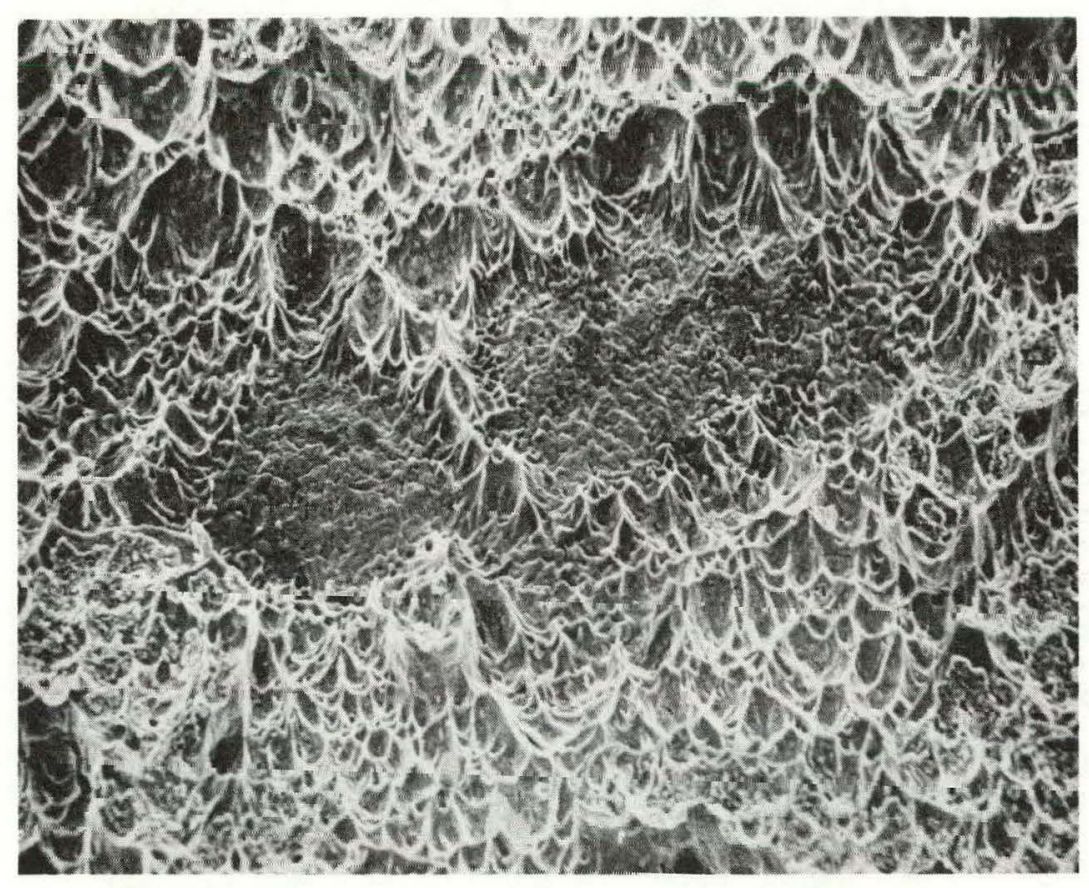




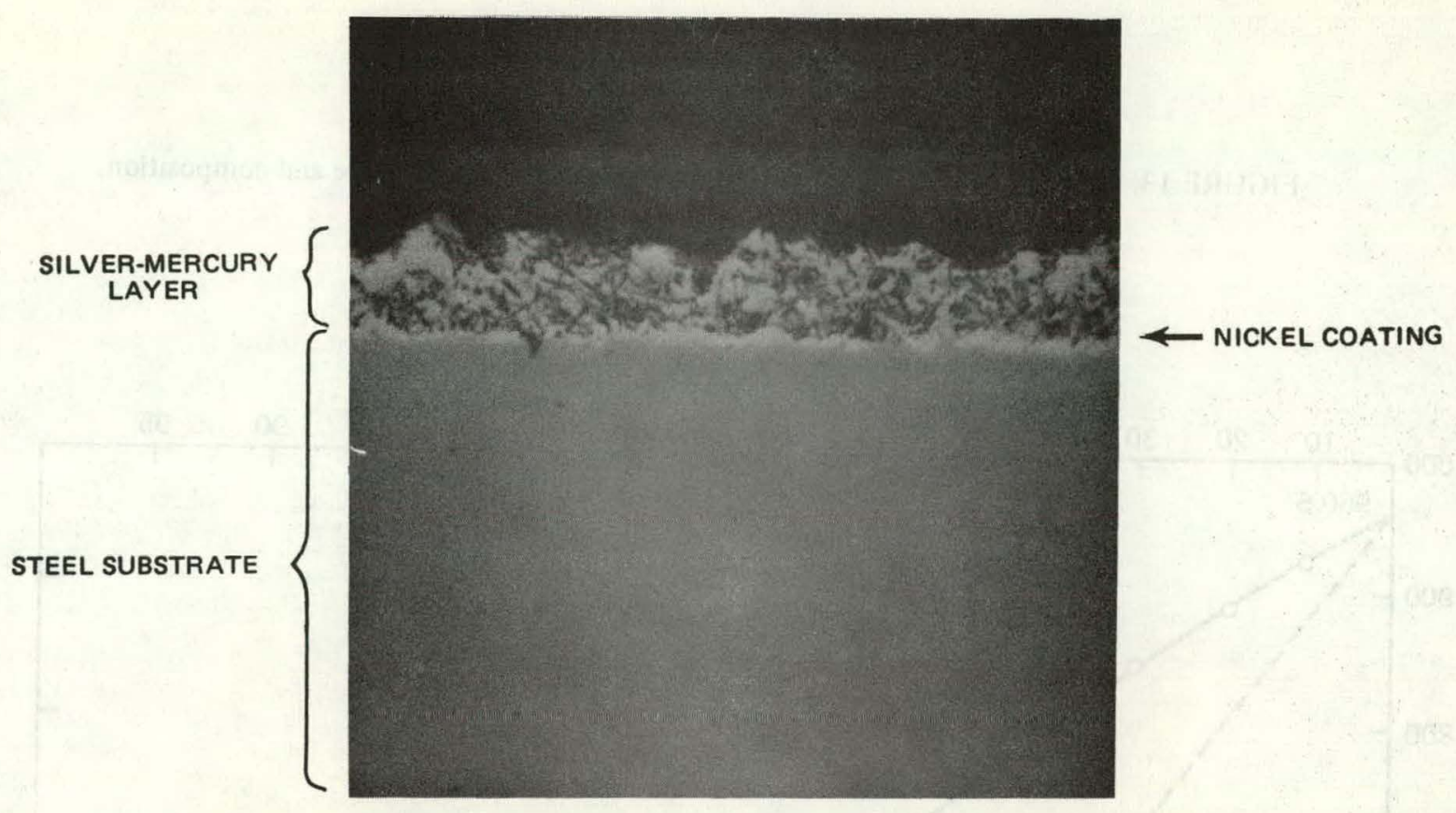

FIGURE 11. Optical micrograph of a fractured mercury-activated silver solid-state bond between maraging steel parts. (Transverse view after tensile testing. Separation occurred at the silver-to-silver interface.) Magnification 800X.

FIGURE 12. Optical micrograph of a fractured mercury-activated silver solid-state bond showing the fracture transition (arrow) from the silver-silver interface to the silver-maraging steel interface. Magnification 800X.

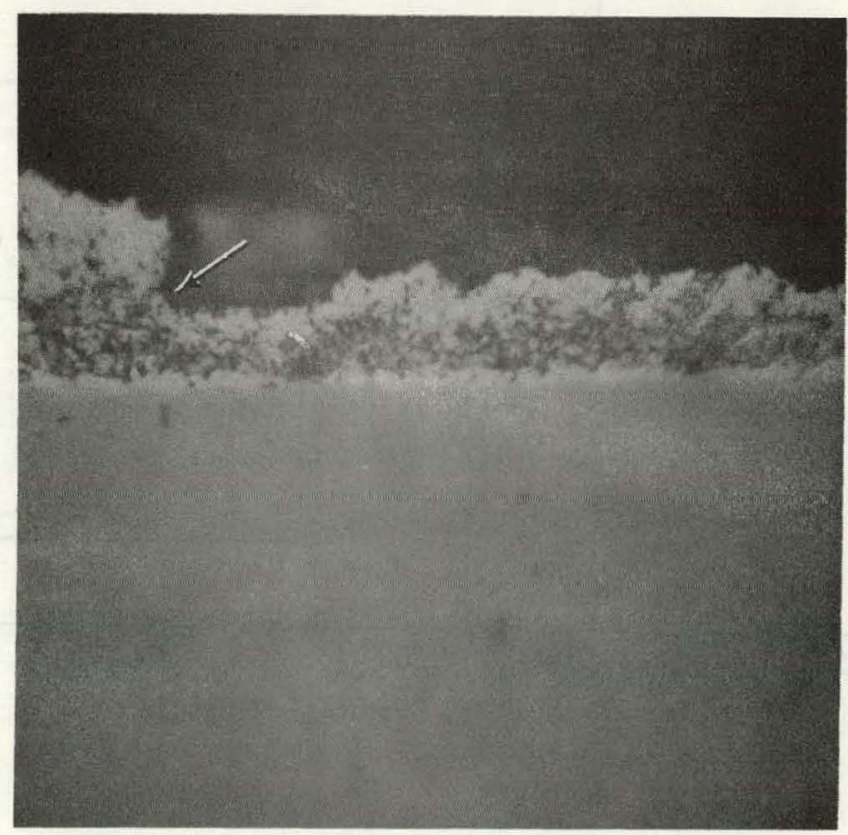


FIGURE 13. Silver-mercury phase equilibria as a function of temperature and composition.

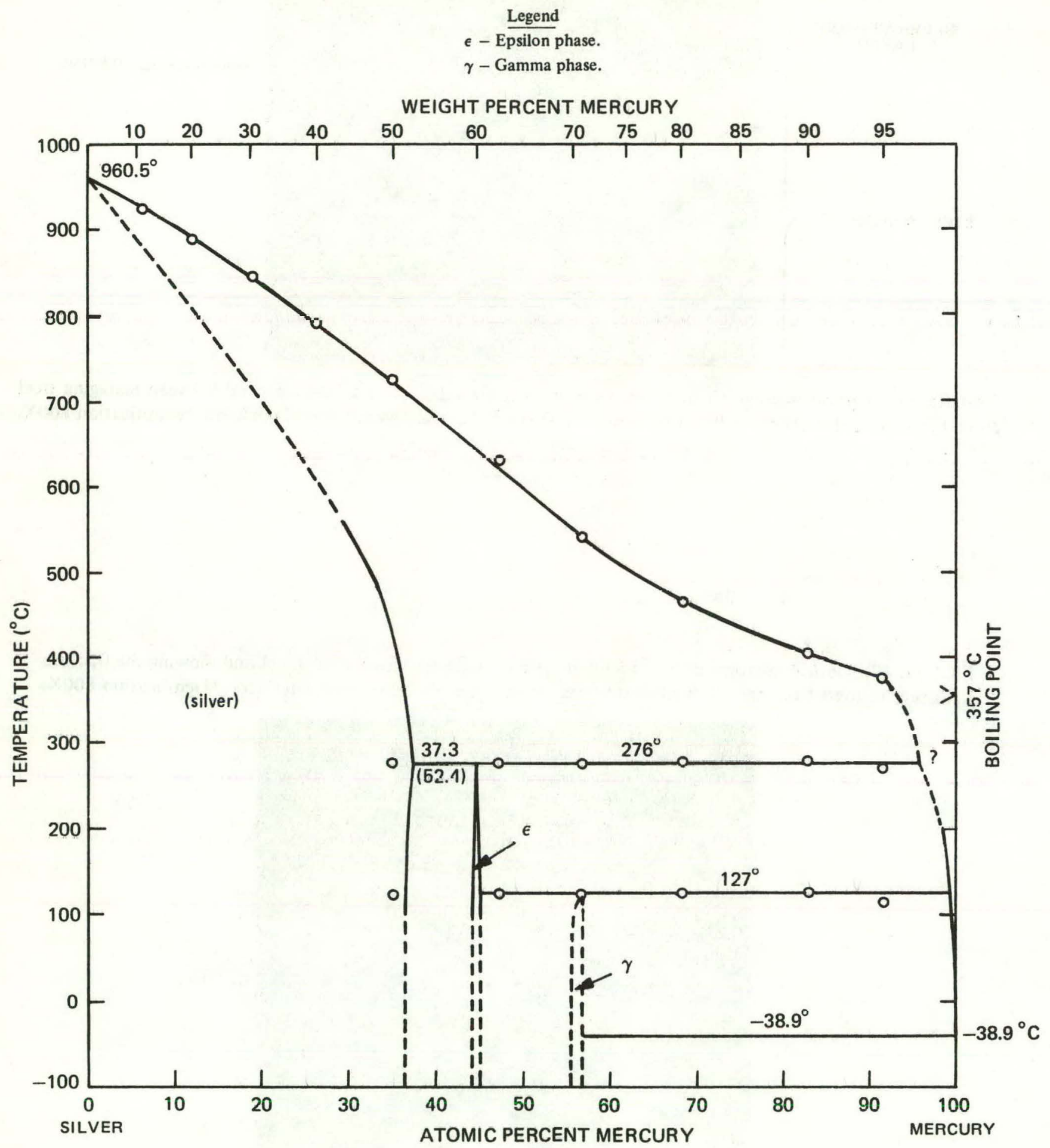


FIGURE 14. Mercury composition scan across the silver bonding layer.

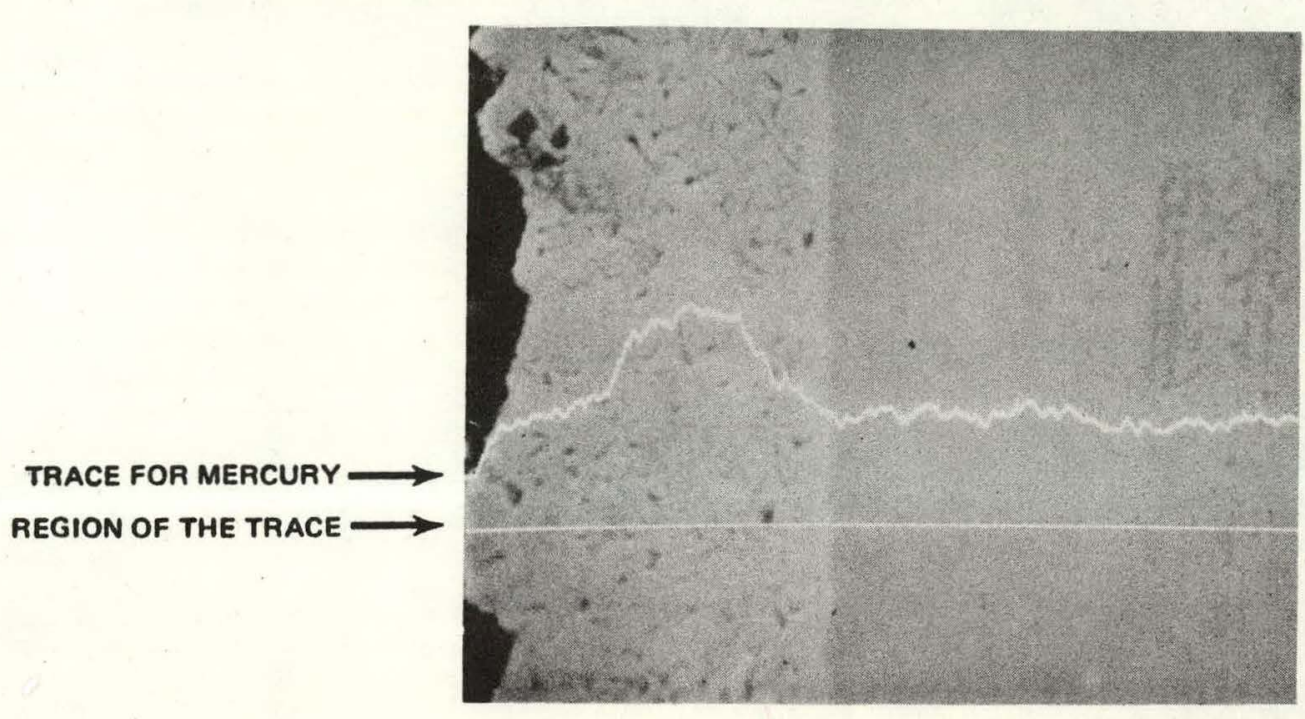


RFP-2514

\section{THIS PAGE \\ WAS INTENTIONALLY \\ LEFT BLANK}

